\title{
GESTÃO TERRITORIAL E O PROGRAMA DE INFRAESTRUTURA E SERVIÇOS (PROINF) NO MÉDIO SERTÃO DE ALAGOAS
}

\author{
Juliana Antero da Silva ${ }^{1}$ \\ Priscila Pereira Santos ${ }^{2}$
}

\begin{abstract}
Resumo
O objetivo geral desta pesquisa foi analisar a gestão territorial no Médio Sertão de Alagoas sob a perspectiva das ações dos Projetos de Infraestrutura e Serviços (PROINF). Este estudo tem como delineamento os seguintes procedimentos metodológicos, a saber: pesquisa bibliográfica, pesquisa documental e pesquisa de campo. Observou-se maior participação dos atores sociais nas plenárias do Colegiado que tratavam das chamadas para o PROINF. Nesse contexto, o PROINF apresenta-se como a chave de atração para o Colegiado, no entanto, também pode apresentar força inversa. No Colegiado, o espaço de discussão torna-se arena de poder na tomada de decisões. $\mathrm{O}$ interesse de determinado grupo é evidenciado. Isso, tende a excluir os grupos ou associações não participantes. Assim, a proposta de coletividade é sucumbida por um processo perverso e desagregador.
\end{abstract}

Palavras-chave: Agricultura familiar; território da cidadania; desenvolvimento territorial.

\section{TERRITORIAL MANAGEMENT AND THE INFRASTRUCTURE AND SERVICES PROGRAM (PROINF) IN THE MIDDLE SERTÃO DE} ALAGOAS

\begin{abstract}
The general objective of this research was to analyze the territorial management in the Middle Sertão of Alagoas from the perspective of the actions of the Infrastructure and Services Projects (PROINF). This study is designed with the following methodological procedures, namely: bibliographic research, documentary research and field research. Greater participation of the social actors was observed in the plenary sessions of the Collegiate that dealt with the calls to PROINF. In this context, PROINF presents itself as the key of attraction for the Collegiate, however, it can also present inverse force. In the Collegiate, the space for discussion becomes an arena of power in decision making. The interest of a certain group is evident. This tends to exclude non-participating groups or associations. Thus, the collective proposal is succumbed by a perverse and disintegrating process.
\end{abstract}

Keywords: Family farming; citizenship territory; territorial development.

\footnotetext{
${ }^{1}$ Mestra em Geografia pelo Programa de Pós-graduação em Geografia da Universidade Federal de Sergipe (PPGEO/UFS). Professora de Geografia do Município de Pilar/AL. E-mail: julianaantero@ hotmail.com

${ }^{2}$ Doutora em Geografia pelo Programa de Pós-graduação em Geografia da Universidade Federal de Sergipe (PPGEO/UFS). E-mail: p.p.s2902@gmail.com
} 


\section{GESTIÓN TERRITORIAL Y PROGRAMA DE INFRAESTRUCTURA Y SERVICIOS (PROINF) EN EL SERTÃO MEDIO DE ALAGOAS}

\section{Resumen}

El objetivo general de esta investigación fue analizar la gestión territorial en el Sertão Medio de Alagoas desde la perspectiva de las acciones de los Proyectos de Infraestructura y Servicios (PROINF). Este estudio está diseñado con los siguientes procedimientos metodológicos, a saber: investigación bibliográfica, investigación documental e investigación de campo. Hubo una mayor participación de los actores sociales en las sesiones plenarias de la Junta que trataron los llamados a PROINF. En este contexto, PROINF se presenta como la clave de atracción para el Colegiado, sin embargo, también puede presentar fuerza inversa. En Collegiate, el espacio para la discusión se convierte en una arena de poder en la toma de decisiones. El interés de cierto grupo es evidente. Esto tiende a excluir grupos o asociaciones no participantes. Así, la propuesta colectiva es sucumbida por un proceso perverso y desintegrador.

Palabras clave: Agricultura familiar; territorio de ciudadanía; desarrollo territorial.

\section{INTRODUÇÃO}

Nos países europeus, as políticas públicas no espaço rural entre o final do século XX e o início do século XXI começam a ser reestruturadas sob a perspectiva do desenvolvimento territorial rural. O cenário marcado pelas Guerras e as sucessivas crises do sistema capitalista dão o tom às políticas de descentralização, como ação para promover o bem-estar social, e ao desenvolvimento local por meio de uma abordagem territorial. Estas são estratégias de planejamento, embasadas no modelo button- $u p^{3}$, que ganharam forma na União Europeia com a criação do programa Ligações Entre Ações de Desenvolvimento das Economias Rurais (LEADER). Por ter caráter multissetorial e integrador, a proposta de desenvolvimento territorial do LEADER está centrada na promoção e abertura da competitividade territorial, e na participação de atores sociais no processo de elaboração e fiscalização dos projetos.

No Brasil, os debates sobre o desenvolvimento aparecem mediante os entraves históricos do rural. Em meados da década de 1990, a implantação de políticas públicas sob uma nova estratégia de desenvolvimento e planejamento emerge diante das pressões dos movimentos sociais, sindicais e da própria necessidade de combate e superação da pobreza rural, principalmente no Nordeste e no Norte do país. Nesse contexto, destacam-se as políticas

\footnotetext{
3 O modelo button-up apresenta-se como uma estratégia orientada de baixo para cima, os planos de desenvolvimento local são elaborados de forma descentralizada.
} 
públicas direcionadas a agricultura familiar, notadamente o Programa Nacional de Fortalecimento da Agricultura Familiar (PRONAF) criado em 1996.

O PRONAF foi o primeiro programa ou política pública implantado no Brasil direcionado especificamente para o meio rural mais pobre. O PRONAF tinha como finalidade promover o desenvolvimento "sustentável", aumentar a capacidade produtiva, gerar empregos e melhorar a renda dos/das agricultores/as familiares. Este programa apresentou inicialmente três linhas principais de financiamento: Capacitação, Infraestrutura e Serviços e Crédito Rural.

A linha de financiamento Infraestrutura e Serviços do PRONAF esteve em execução apenas entre 1996 e 2002. A inserção desta linha em escala municipal apresentou conflitos e contradições que provocaram mudanças na sua política e na sua escala de atuação. Em 2003, essa linha integrou-se ao Programa Nacional de Desenvolvimento Sustentável dos Territórios Rurais (PRONAT) e passou a denominar-se "Ações de Projetos de Infraestrutura e Serviços" (PROINF). Na adequação ao PRONAT, o PROINF começa a atuar na dimensão territorial. O PROINF tem como objetivo financiar projetos de infraestrutura e serviços indutores do desenvolvimento territorial. Ademais, o PROINF tem como finalidade contemplar projetos de implantação de agroindústrias, armazenamento de produtos, estruturas de comercialização, apoio a gestão territorial, transporte, entre outros.

É digno de registro que, nos anos 2000, o Ministério do Desenvolvimento Agrário (MDA) criou a Secretaria de Desenvolvimento Territorial (SDT). E, sob a influência da experiência inovadora do LEADER, em 2003, estrutura-se o Programa Nacional de Desenvolvimento Sustentável dos Territórios Rurais (PRONAT). Em 2008, cria-se o Programa Território da Cidadania (PTC) com a finalidade de atender a agricultura familiar e minimizar os problemas no espaço rural sob a perspectiva da abordagem territorial. No Brasil, 120 Territórios da Cidadania (TCs) foram configurados. A região Nordeste apresenta 56 Territórios, um pouco mais de $46 \%$ do total nacional.

No Nordeste brasileiro, especificamente em Alagoas, a articulação do PROINF apresenta um evidente descompasso entre a implantação da infraestrutura e dos serviços (SANTOS; OLIVEIRA; COSTA, 2016; RODRIGUES; NASCIMENTO; SILVA, 2016). A infraestrutura é implantada na materialização dos objetos técnicos, como por exemplo, tratores, caminhões, motocicletas, abatedouros, fábricas-escola, tanques de refrigeração, entre outros. O funcionamento dos objetos técnicos depende indissociavelmente das ações, que por 
sua vez, demandam conhecimento, ou, em outros termos, serviços de capacitação profissional, que não chegam simultaneamente com os objetos.

No Território da Cidadania do Médio Sertão alagoano, as ações do PROINF ancoramse nos projetos de infraestrutura. A obra e a compra de equipamentos para a construção do abatedouro frigorífico é a mais expressiva. $\mathrm{O}$ abatedouro frigorífico visa atender a cadeia produtiva da ovinocaprinocultura. Os demais PROINFs presentes no Território são compostos por projetos menores que se complementam ao abatedouro frigorífico. Entre os anos 2005 e 2015, 13 projetos de infraestrutura e serviços foram contabilizados.

Os projetos do PROINF têm como finalidade dinamizar a produção da agricultura familiar e tecnificar o campo. As decisões dos projetos de relevância para o Território da Cidadania são tomadas no processo de gestão territorial. Em outras palavras, a condução das propostas manifesta-se na articulação entre o poder público e o poder da sociedade civil. Nesse sentido, o objetivo geral desta pesquisa foi analisar a gestão territorial no Médio Sertão de Alagoas sob a perspectiva das ações dos Projetos de Infraestrutura e Serviços (PROINF).

\section{PROCEDIMENTOS METODOLÓGICOS}

Nesta análise, o recorte temporal situa-se no período entre 2005 e 2017, ou seja, desde o primeiro PROINF proposto no Médio Sertão. Os anos de 2014, 2015, 2016 e 2017 foram analisados mais de perto, em virtude da atuação técnica do Núcleo de Extensão em Desenvolvimento Territorial (NEDET) da Universidade Federal de Sergipe (UFS). Obteve-se acesso ao acervo de documentos, como por exemplo, as atas, as listas de frequência, e, principalmente, os registros das discussões. Estes documentos facilitaram a coleta de dados, sobretudo qualitativos.

Esta pesquisa possui abordagem qualitativa. Desse modo, as análises foram delineadas na articulação entre a pesquisa bibliográfica, documental e de campo. O levantamento e a leitura das bibliografias foram realizados com base nos seguintes temas: PROINF, território e gestão territorial. As análises das produções acadêmicas sobre o PROINF foram embasadas principalmente em Santos, Oliveira e Costa (2016), Rodrigues, Nascimento e Silva (2016), Souza, S. (2015). Sobre território, os principais autores que nortearam as reflexões foram: Souza (2015), Saquet (2010) e Raffestin (1993). Deve-se mencionar a interpretação de "Território" no eixo institucional, ou seja, o da Secretaria de Desenvolvimento Territorial (SDT). É válido mencionar que se faz uso de "território", em minúsculo, para fazer referência 
a categoria geográfica e o "Território" em maiúsculo para identificar a escala institucional de planejamento da SDT. A fundamentação teórico-metodológica sobre a gestão territorial foi ancorada em Delgado e Grisa (2014), Cançado, Tavares e Dallabrida (2013) e Diniz (1996).

A pesquisa documental consistiu na análise dos seguintes materiais: atas e lista de frequência do Colegiado de Desenvolvimento Territorial (CODETER) do Médio Sertão; dados do Censo Agropecuário; Censo Demográfico; Pesquisa agropecuária municipal; Referencial de Apoio aos Territórios Rurais; Plano Territorial do Desenvolvimento Rural Sustentável (PTDRS); Revista dos Territórios da Cidadania; Manuais operacionais do PROINF; Mapas Temáticos; e dados e informações disponíveis no Portal dos Núcleos de Extensão em Desenvolvimento Territorial (NEDETs) e no Sistema de Informações Territoriais (SIT).

$\mathrm{Na}$ pesquisa de campo, fez-se uso das seguintes técnicas: observação participante; registro fotográfico; entrevista informal; e, entrevista semiestruturada em amostragem bolade-neve. A observação participativa versou pela presença nas plenárias do CODETER junto ao NEDET como representação da Universidade Federal de Sergipe (UFS). O NEDET é uma estratégia implantada pela extinta SDT/MDA com a finalidade de operacionalizar ações com base na inclusão produtiva da gestão territorial dos Territórios. As observações foram realizadas nos dias, 13 de outubro de 2016; 14 e 15 de setembro de 2016; 25 de janeiro de 2017 e 08 e 20 de fevereiro de 2017. Além da participação nas plenárias, trabalhos de campo em oito dos nove municípios do Território da Cidadania do Médio Sertão também foram realizados. Analisou-se a agricultura familiar fora dos espaços de atuação do Colegiado. Durante os trabalhos de campo nos municípios foram realizadas entrevistas informais com os/as agricultores/as familiares.

As entrevistas das representações do poder público e da sociedade civil foram realizadas durante as plenárias do CODETER. O roteiro de entrevista foi semiestruturado com perguntas que conforme a resposta do entrevistado abria a possibilidade de elaborar outras questões. Aos/as agricultores/as familiares indagou-se: (i) Como tem funcionado o Colegiado? (ii) Qual a importância do Colegiado como instância de discussão? (iii) Existem conflitos institucionais do CODETER com as entidades do Colegiado? (iv) Como você avalia a participação do proponente, da deliberação e articulação com os outros municípios que integram o Território da Cidadania? 
Assim, este estudo, além da introdução, dos procedimentos metodológicos e as considerações finais, apresenta mais dois momentos. Inicialmente, contextualiza-se o PROINF no Território da Cidadania do Médio Sertão de Alagoas. Em seguida, analisa-se a formação da Gestão Territorial por redes de poderes multiescalares ao discutir-se sobre: a Comissão de Implantação de Ações Territoriais (CIAT) e o Plano Territorial do Desenvolvimento Rural Sustentável (PTDRS) do Médio Sertão; o Colegiado de Desenvolvimento Territorial (CODETER) e os atores sociais; o PROINF como chamariz para os/as agricultores/as familiares nas plenárias do CODETER; e, a atuação dos/as agricultores/as familiares no Colegiado.

\section{PROINF NO TERRITÓRIO DA CIDADANIA DO MÉDIO SERTÃO DE ALAGOAS}

O estado alagoano é marcado pela forte presença da agroindústria canavieira. A concentração fundiária desenha o processo de organização territorial do estado, principalmente com a participação da atividade canavieira no litoral. Segundo Carvalho (2009), a representação política propiciada pelo cultivo da cana e do monopólio agroindustrial é marcada pelo modelo conservador. As regiões canavieiras obstaculizam a inserção de uma cultura produtiva democrática, o que contribui para o mais alto grau de desigualdade e estagnação social entre as regiões brasileiras.

Em Alagoas, as políticas públicas para a agricultura familiar até meados da década de 1990 não fogem à regra nacional. Carvalho (2008) cita que na década de 1990, os pequenos estabelecimentos, na sua ampla maioria, não tinham assistência técnica, recursos para o custeio e investimentos, e capacidade para comercialização, por isso, apresentavam baixa produtividade. Os grandes estabelecimentos localizam-se nas melhores terras, contavam com mais infraestrutura e tinham o acesso e as facilidades negadas à maioria das pequenas propriedades.

A organização espacial produtiva apresenta-se como reflexo da questão social e das relações de produção que se estabeleceram ao longo dos séculos no estado. Há uma inegável concentração de riquezas no estado de Alagoas. Riquezas estas produzidas pela agroindústria e a concentração fundiária, ao fixar nas mãos de poucos o controle econômico e também político. O monopólio da terra e a desigualdade social contribuem para que o estado de Alagoas tenha o menor Índice de Desenvolvimento Humano (IDH), 0,631, dentre os estados do Nordeste. É digno de registro que o IDH é estatisticamente calculado com base no índice 
da expectativa de vida ao nascer, nos dados sobre a educação e no Produto Interno Bruto (PIB) do país (IBGE, 2010).

Diante destes dados e das reivindicações dos/as agricultores/as familiares, a agricultura familiar em Alagoas vem sendo engajada nas políticas voltadas para o campo. $\mathrm{O}$ processo de implantação do Programa Nacional de Desenvolvimento Sustentável dos Territórios Rurais (PRONAT) inicia em 2004 com a criação da Comissão de Implementação das Ações Territoriais (CIATs). Em 2008, os Territórios da Cidadania (TCs) foram criados a partir dos critérios elaborados pela SDT/MDA. Pelo IDH, anteriormente apresentado, verifica-se que as características socioeconômicas do estado de Alagoas correspondem aos critérios definidos pelo Programa Territórios da Cidadania (PTC) para que os municípios façam parte da política territorial, são eles: população de baixa renda, alta taxa de analfabetismo e população vulnerabilidade social.

O estado de Alagoas apresenta 06 (seis) TCs: Territórios da Bacia Leiteira; do Agreste; do Alto Sertão; do Litoral Norte; do Médio Sertão; e da Mata Alagoana (Mapa 1). Especificamente o Território da Cidadania do Médio Sertão, que aqui nos interessa mais de perto, abrange uma área de $2.542,4 \mathrm{Km}^{2}$ e representa aproximadamente $10 \%$ da área total do estado, conforme o IBGE (2010). O referido Território configura-se geograficamente em 09 (nove) municípios localizados na região semiárida de Alagoas, a saber: Carneiros, Dois Riachos, Maravilha, Olivença, Ouro Branco, Poço das Trincheiras, Santana do Ipanema, São José da Tapera e Senador Rui Palmeira (Mapa 2).

Mapa 1: Territórios da Cidadania em Alagoas Mapa 2: Território do Médio Sertão alagoano

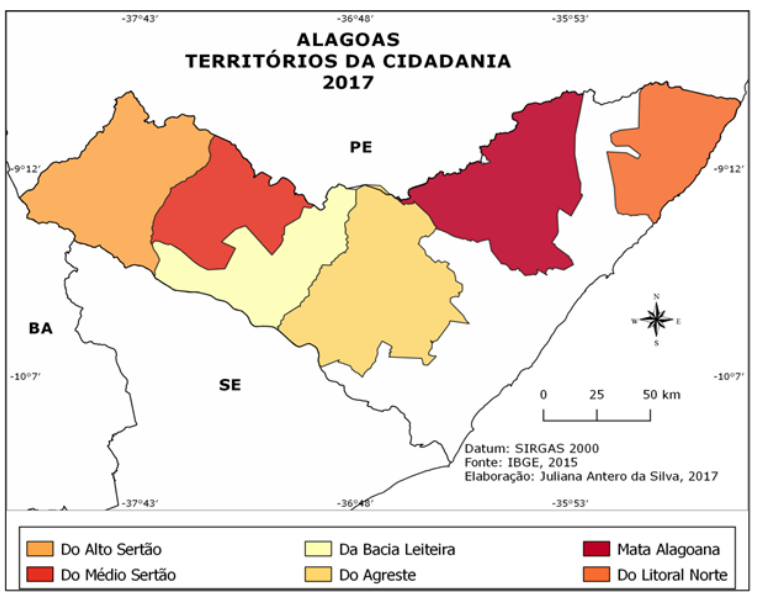

Fonte: Silva, 2017.

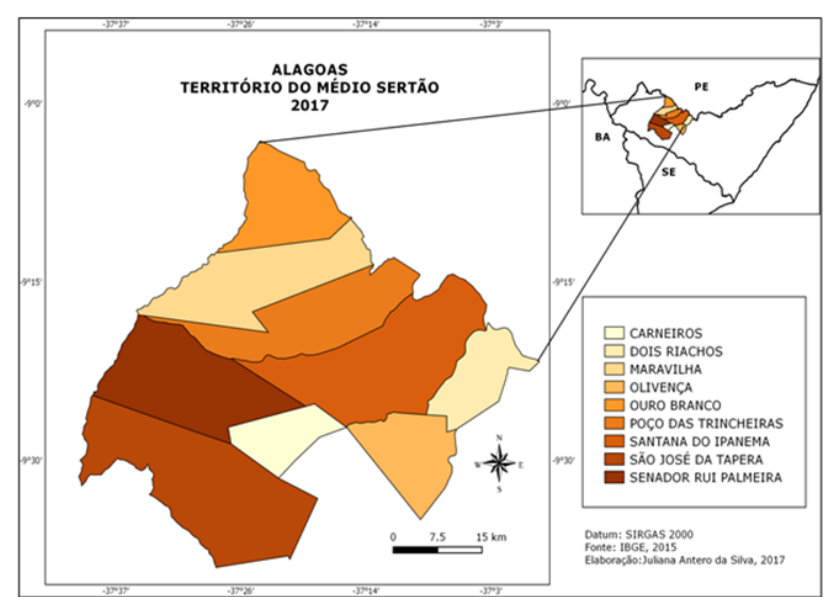

Fonte: Silva, 2017. 
O PROINF apresenta significativa expressão territorial quando comparado com outras políticas públicas para o campo no Médio Sertão. A proposta de "eficácia" em curto prazo e a dinamização da produção, através da construção, compra e/ou reformas de projetos de infraestrutura e serviço, são as principais deliberações do PROINF. Esses propósitos funcionam como elementos convidativos aos/as agricultores/as familiares. É a possibilidade de adquirir competitividade territorial, pois, se aposta na inovação tecnológica disponibilizada pela infraestrutura fornecida pelos projetos do PROINF. Se anteriormente ter um trator para arar a terra fazia parte de um "sonho" distante, o PROINF aponta a possibilidade de ações imediatas para a transformação do "sonho" em realidade. Assim, o imediatismo e os investimentos também são elementos que atraem os/as agricultores/as familiares.

Entre os anos de 2005 e 2014, treze PROINFs foram direcionados para o Médio Sertão. Os projetos foram distribuídos nas linhas de atuação infraestrutura e apoio a gestão. Ao total foram investidos $\mathrm{R} \$ 2.400 .848,00$ (dois milhões, quatrocentos mil, oitocentos e quarenta e oito reais) nesses nove anos (Gráfico 01).

Os primeiros projetos aprovados foram em 2005, ano que apresentou um número expressivo de ações do PROINFs e de recursos investidos, cerca de $\mathrm{R} \$ 728.688,00$. Nos anos seguintes há uma redução significativa de PROINFs para o Médio Sertão, de 6 (seis) ações em 2005, para somente 1 (uma), nos anos de 2006, 2007, 2010, 2013 e 2014. Somente no ano de 2008 foram registrados 2 (dois) PROINFs. Diante disto, o ano 2005, período de lançamento dos PROINFs do Médio Sertão, concentrou 50\% dos contratos.

Gráfico 01: Financiamentos PROINF 2005-2014

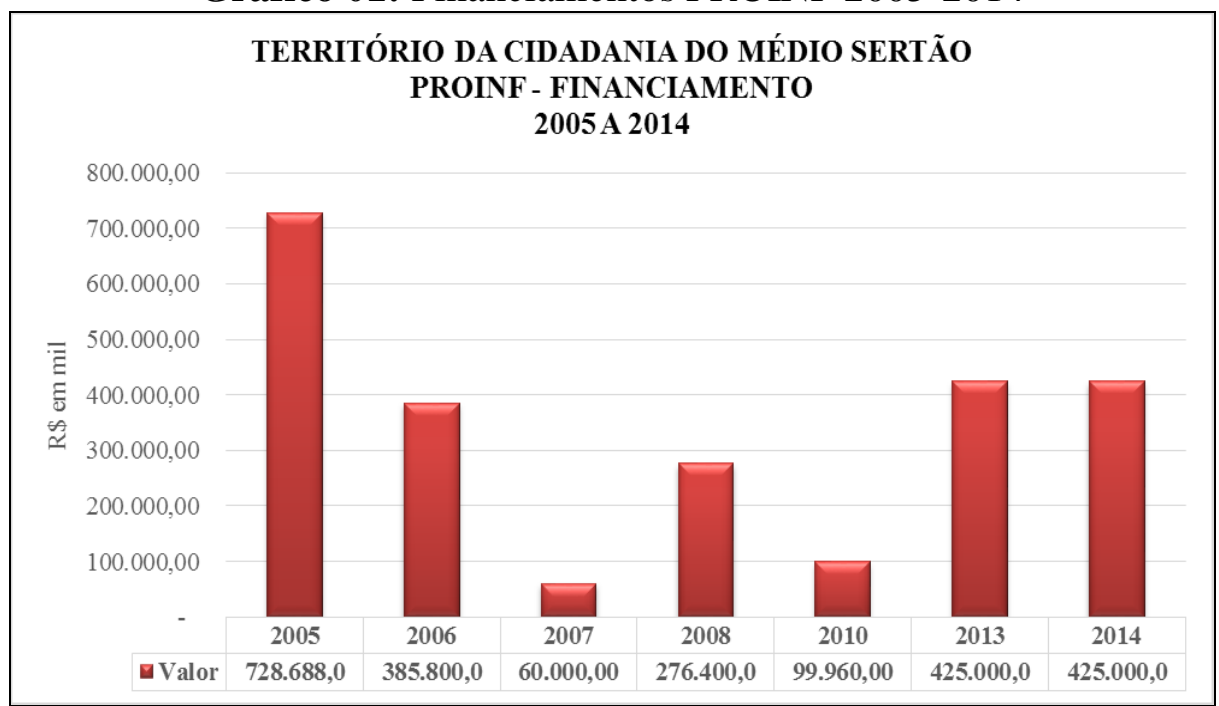

Fonte: CEF (04/05/2015; CGMA/SDT (junho/2015).

Elaboração: Juliana Antero da Silva, 2018 
Dentre os PROINF's aprovados, os que tiveram maior financiamento foram: $a$ Construção e Equipamento do Frigorífico, em 2006, no valor de $\mathrm{R} \$ 385.800$ mil, e o Fortalecimento da Produção agropecuária pelo Uso Coletivo de Tratores e Implementos no ano de 2014, com crédito de R\$ 425 mil. As demais ações foram para complementar o PROINF 2006.

Os recursos financeiros disponibilizados para as ações de infraestrutura e serviço do PROINF no Médio Sertão de Alagoas agem como forças centrípetas na atração dos/as agricultores/as familiares. Observa-se também um interesse efervescente dos gestores municipais na elaboração de propostas para submeter à aprovação dos projetos. Assim, a disputa territorial via PROINF, em tempos de globalização, tende a valorizar, ou revalorizar, os territórios no processo de competitividade mercadológica (SANTOS, 2013). Diante deste campo de forças, para usar a expressão de Raffestin (1993), o PROINF aponta para a formação de divergências territoriais, principalmente conflitos entre os gestores públicos.

\section{GESTÃO TERRITORIAL: REDES DE PODERES MULTIESCALARES}

O debate sobre governança versa sobre o novo momento do exercício atuante do poder público e da sociedade civil em gerenciar o planejamento para o desenvolvimento territorial rural. Ao compreender que os espaços de atuação da gestão do Colegiado se reproduzem pela interrelação de poder optou-se por utilizar o conceito de gestão territorial (CANÇADO; TAVARES; DALLABRIDA, 2013).

A palavra governança tem sido bastante enfatizada na atualidade. Embora o termo governança seja um complemento da governabilidade, o conceito é mais amplo. Segundo Diniz (1996, p. 09), a governança "refere-se ao conjunto dos mecanismos e procedimentos para lidar com a dimensão participativa e plural da sociedade, o que implica expandir e aperfeiçoar os meios de interlocução e de administração do jogo de interesses". Pressupõe-se a flexibilidade do Estado e a ampliação da participação dos atores sociais, ou seja, tem-se como base a interrelação do poder público em suas diferentes instâncias e da sociedade civil na condução das políticas públicas. Nesta nova perspectiva de gestão, a partir da governança, o poder público e os representantes da sociedade civil são compreendidos como atores sociais “ativos" no Território. A concepção "descentralizada" de gestão nos Territórios da Cidadania visa à articulação da governança com a proposta do PTC para apresentar-se como um instrumento de desenvolvimento territorial rural. 
No âmbito do PTC, a proposta de governança ancora-se, principalmente, no Colegiado de Desenvolvimento Territorial (CODETER) e se apresenta organizada na interação vertical, com a composição dos entes federativos, poder federal e estadual; e na dimensão horizontal, na composição a nível territorial, materializado na interrelação do poder público e da sociedade civil. Nesta perspectiva, analisa-se a "nova" governança, não mais sustentado na dominação total do Estado soberano, mas priorizando os interesses coletivos e a prática da democracia (CANÇADO; TAVARES; DALLABRIDA, 2013). Nas arenas democráticas formadas pelo Colegiado, as ações e os projetos das políticas públicas tendem passar por um processo de fiscalização e tomada de decisão.

Segundo o Conselho Nacional de Desenvolvimento Rural Sustentável (CONDRAF), o Colegiado deve configurar-se com no mínimo as seguintes instâncias: Plenário ou Plenária, Núcleo Diretivo ou Dirigente e Núcleo Técnico. A ampliação da participação poderá ser através da criação de Câmaras Temáticas ou Técnicas e Comitês Setoriais, Temáticos ou Técnicos (BRASIL, 2010) (Figura 1).

O Plenário, ou Plenária, funciona como a instância máxima do Colegiado, incumbida de deliberar e tomar decisões estratégicas para o Território. O Núcleo Dirigente ou Diretivo desempenha a função de coordenar as ações no Plenário e articular os atores sociais e as políticas públicas com vista ao desenvolvimento territorial e somente os atores que fazem parte do Colegiado participam do Núcleo Dirigente.

Figura 1: Estrutura do Colegiado de Desenvolvimento Territorial - CODETER

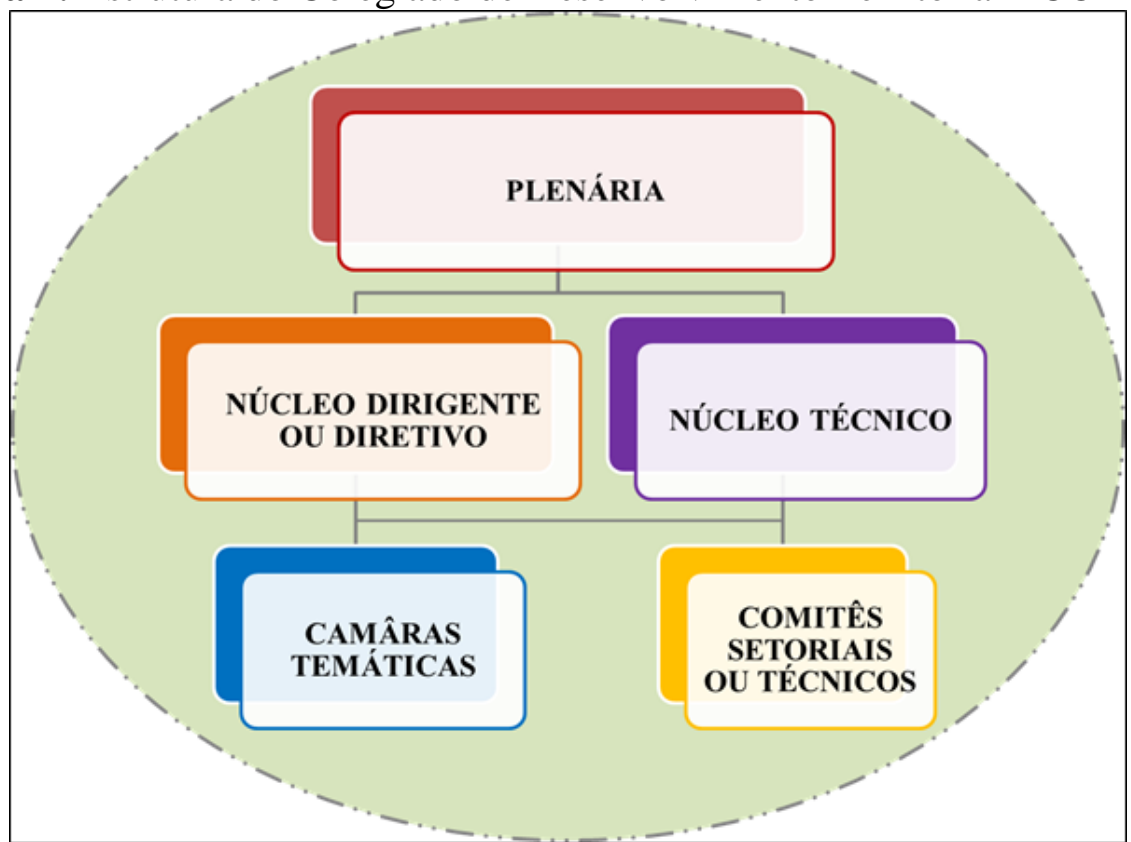

Fonte: Brasil, 2010

Elaboração: Autores 
O Núcleo Técnico apresenta-se como instância de apoio. Este Núcleo é composto por instituições de ensino, pesquisa, assistência técnica, dentre outros. Para participar do Núcleo Técnico não há obrigatoriedade de ser integrante do Colegiado. Assim, qualquer organização de assistência ou cooperação pode ser inserida. As Câmaras Temáticas e os Comitês Setoriais ou Técnicos constitui formação proposta pelo Colegiado para debater assuntos específicos do Território. As Câmaras têm o papel de apoiar, fortalecer e articular grupos específicos. As formações das Câmaras Temáticas e Comitês Setoriais ou Técnicos não estão restritas ao plenário. Através destas instâncias busca-se refletir e tratar do segmento excluído das políticas (DELGADO; GRISA, 2014).

Como se vê, o modelo de governança territorial mostra-se complexo, pois envolve a participação de uma pluralidade de atores sociais. Os arranjos institucionais dos Colegiados territoriais "incorpora interesses específicos tornando-se inerentemente conflituosa a relação entre os agentes. Por decorrência, tais arranjos exigem processo decisório diferente do modelo burocrático racional, típico das hierarquias" (CANÇADO; TAVARES; DALLABRIDA, 2013, p. 338). O diálogo neste modelo de governança assume centralidade. Nesse contexto, a gestão é territorial uma vez que se estrutura "através da atuação dos diferentes atores, nas instituições, incluindo o Estado, e organizações da sociedade civil, em redes de poder socioterritorial". (CANÇADO; TAVARES; DALLABRIDA, 2013, p. 331, grifo dos autores). Assim, as redes de poder se articulam num processo de interação multiescalar.

Sob a perspectiva desenvolvimento territorial rural, a criação dos espaços de diálogo foi iniciada pelas Comissões de Implantação de Ações Territoriais (CIATs) e consolidada pelos Colegiados de Desenvolvimento Territorial (CODETERs). Segundo o PTDRS do Médio Sertão, a CIAT promoveu encontros, debates, viagens de intercâmbios e oficinas no intuito de envolver todos os segmentos do governo e da sociedade civil. Esta articulação entre representantes do Estado e dos atores sociais objetivou criar arranjos institucionais com o envolvimento de redes de organizações, movimentos sociais, instituições públicas e privadas para compor o desenho de ações dos projetos territoriais balizados pelas informações do Território.

\section{A Comissão de Implantação de Ações Territoriais (CIAT) e o PTDRS do Médio Sertão}

O primeiro arranjo institucional do Médio Sertão foi elaborado sob a perspectiva de implantar e operacionalizar a cadeia produtiva de ovinos e caprinos. A construção do 
abatedouro frigorífico apresentava como proposta atender os nove municípios. O arranjo institucional para planejar este processo foi composto por instituições financeiras, Ministérios, ONGs, a Prefeitura de Santana do Ipanema como proponente da ação, secretarias de agricultura, institutos fundiários e a comunidade civil (PTDRS, 2010). Neste contexto, as institucionalidades são territorializadas nos "espaços de expressão, discussão, deliberação e gestão, que congregam a diversidade de atores sociais e cuja atenção é voltada à gestão social das políticas e dos processos de desenvolvimento" (BRASIL, 2005, p. 11). Os arranjos institucionais tornam-se peças-chave para o planejamento e a gestão do desenvolvimento territorial rural do Médio Sertão.

O entrevistado I de um dos municípios do Território da Cidadania do Médio Sertão faz referência à participação do Colegiado na construção do PTDRS. "Еu participei dele [construção do PTDRS], participou organizações não governamentais, prefeitura, empresas particulares e associações" (Entrevistado I, 2016, [sic]). Contudo, uma parcela dos representantes das associações da agricultura familiar, em entrevista, diz desconhecer o PTDRS. Pode até ser que as associações e os/as agricultores/as familiares estivessem presentes, mas será que compreendiam o processo vivenciado? Será que estes atores, mesmo presentes, representavam poder decisório?

O auditório onde se realizavam as reuniões é o território que se consolida pelo poder do conhecimento. No Território do Médio Sertão, as relações de poder sobre este espaço geográfico estruturam-se nos discursos realizados no território configurado pelo auditório. Corrobora-se com Milton Santos (2012), "o conhecimento exerceria assim - e fortemente seu papel de recurso, participando do clássico processo pelo qual, no sistema capitalista, os detentores de recursos competem vantajosamente com os que deles não dispõem" (SANTOS, 2012, p. 243). Nas arenas democráticas inicia-se a construção de um Plano de quem conhece o PTDRS e o Território, porém desconhece os territórios dos principais interessados, os/as agricultores/as familiares, e de quem conhece seus territórios, mas desconhece o PTDRS.

O território é constituído pelas relações sociais que são produzidas sobre determinado espaço valorizado e embutido de poder (SOUZA, 2015; RAFFESTIN, 1993). E, as relações sociais são construídas na territorialidade. Segundo Saquet (2010, p. 129), a territorialidade é percebida como "o acontecer de todas as atividades cotidianas, seja no espaço de trabalho, do lazer, da igreja, da família, da escola etc., resultado e determinante do processo de produção de cada território [...]”. Contudo, a análise conceitual de Território no lançamento do 
Programa Território da Cidadania aparece sintetizada no seguinte conceito: “o território é formado por um conjunto de municípios com mesma característica econômica e ambiental, identidade e coesão social, cultural e geográfica" (REVISTA TERRITÓRIOS DA CIDADANIA, 2009, p. 03). Deve-se mencionar que este conceito se aproxima, segundo a perspectiva geográfica, da categoria de região. Por isso, buscou-se diferenciar território enquanto categoria geográfica e Território do planejamento.

Os "donos" do conhecimento sobre as particularidades e potencialidades produtivas do Médio Sertão Alagoano são os/as agricultores/as familiares. Em outras palavras, é o valor particular dos aspectos multidimensionais do "vivido" pelos membros de uma coletividade que produz o território (RAFFESTIN, 1993). É no território que o/a agricultor/a familiar exerce seu poder e produz sua territorialidade que também está ligada à sua identidade ao lugar e conectada a vivência e experiência do cotidiano.

\section{Colegiado de Desenvolvimento Territorial (CODETER) e os atores sociais}

Os Colegiados Territoriais desempenham o papel de colocar em prática as demandas e as necessidades dos/as agricultores/as familiares a partir das particularidades de cada Território. Destina-se, portanto, aos atores sociais a condução e o sucesso dos projetos. No Território do Médio Sertão, entre os anos de 2014 e 2015, houve ao total 14 plenárias: 07 plenárias no ano de 2014 e 07 plenárias no ano de 2015. No ano de 2016, por indisponibilidade dos dados completos, foram analisadas 04 plenárias, nos meses de janeiro, março e agosto. Segundo as análises de Rodrigues (2015)4, entre 2014 e 2015, 69\% das propostas dos PROINFs foram elaboradas pelo poder público e $31 \%$ pela sociedade civil organizada. Embora a representação da sociedade civil tenha sido maior tanto no ano de 2014 quanto no ano de 2015. No ano de 2014, a sociedade civil esteve representada por 51 pessoas e por 29 representantes do poder público. No ano de 2015, 36 pessoas representavam a sociedade civil e 30 pessoas o poder público.

No CODETER, a esfera do poder público é representada por secretarias municipais, secretarias do governo estadual e outras organizações representativas pertencentes ao poder estadual e federal, como Bancos, empresas, órgãos de assistência técnica, entre outros. Como representação da sociedade civil, destacam-se a atuação das seguintes entidades: Associações da Comunidade Quilombola de Carneiros, Senador Rui Palmeira e São José da Tapera;

\footnotetext{
${ }^{4}$ Apresentação técnica elaborada por Rodrigues (2015) enquanto integrante do NEDET/UFS.
} 
Associações Humanitárias, De Entreajuda, Ação Social (ADEJUSA) de São José da Tapera; Centro de Desenvolvimento Comunitário de Maravilha (CDECMA); Sindicato dos Trabalhadores e Trabalhadoras Rurais (STTR) de Santana do Ipanema; STTR São José da Tapera; STTR Poço das Trincheiras; Associações Comunitárias de Santana do Ipanema, Dois Riachos; Pastoral da Criança São Cristóvão; Cooperativa de Criadores de Pequenos Animais de Santana do Ipanema (COPASIL); a União das Cooperativas de Agricultura Familiar e Economia Solidária do Estado de Alagoas (UNICAFES); e, Agroleite (Poço das Trincheiras). O Núcleo técnico é composto pelo Núcleo de Extensão em Desenvolvimento Territorial (NEDET) da Universidade Federal de Sergipe (UFS), a Universidade Federal de Alagoas (UFAL), as Delegacias Federais do Desenvolvimento Agrário (DFDA) e o CODETER.

Ademais, é válido mencionar a atuação das seguintes ONGs: Articulação do Semiárido (ASA); Coordenação da ASA - AL; Arte Cidadania e Meio Ambiente (ACEMA); Caritas Brasileiras - Regional NE 2; Centro de Apoio Comunitário de Tapera em União a Senador (CACTUS); Centro de Desenvolvimento Comunitário de Maravilha (CDECMA); Movimento Minha Terra (MMT); Núcleo de Desenvolvimento Comunitário (NUDEC); Visão Mundial - Micro crédito (parcerias com Cactus/NUDEC); Instituto de Pesquisa dos Municípios do Nordeste (IPDN); ECO Engenho.

No ano de 2014, a "força" representativa dos arranjos institucionais do Território do Médio Sertão destacou-se nos meses de setembro, outubro e novembro, com destaque para a participação da sociedade civil/entidades. Nos referidos meses, a Matriz do Programa Território da Cidadania foi apresentada. Ainda no referido ano, formou-se uma Comissão para discutir e tomar decisões sobre a implantação do Programa Nacional de Educação do Campo (PRONACAMPO). Além disso, verificou-se, pelas pautas das reuniões, a necessidade de discutir sobre a realização de cursos pelo Programa Nacional de Acesso ao Ensino Técnico e Emprego (PRONATEC).

No mês de julho de 2015, analisou-se uma maior representatividade da sociedade civil organizada. Certamente, a discussão sobre as ações do PROINF pode ter motivado o interesse na participação dos atores territoriais. Deve-se mencionar ainda, que no ano 2015, o município de Santana do Ipanema se habilitou como proponente e na oportunidade, havia representantes da Universidade Estadual de Alagoas (UNEAL) que apresentaram a disponibilidade de vagas para o curso de Capacitação em Desenvolvimento da Economia Solidária. 
No ano de 2016, as discussões nas reuniões também exerceram importância e atraiu um considerável número de participantes. Assim como ocorreu nos demais anos, houve meses em que as pautas de discussão parecem ter se apresentado mais interessantes para os representantes do Colegiado. No ano de 2016, não foi diferente, no dia 22 de março foi realizada uma reunião extraordinária com a presença do Prefeito de Santana do Ipanema, isso provocou maior participação das territorialidades do Médio Sertão para esclarecimentos sobre o PROINF, uma vez que Santana do Ipanema se apresenta como proponente de alguns projetos do PROINF estabelecidos nos últimos anos para o Território.

De modo específico, predominou em 2014 a representação civil da Comunidade Quilombola do município de Dois Riachos e do Sindicato dos Trabalhadores Rurais de Santana do Ipanema. No ano de 2015, registrou-se uma maior representação do poder da sociedade civil, com destaque para o Sindicato dos Trabalhadores rurais de São José da Tapera, a Associação de Desenvolvimento da Juventude no Semiárido (ADEJUSA), a Cooperativa dos Criadores de Pequenos Animais de Santana do Ipanema (COPASIL) e a Associação de Jesus de Dois Riachos.

No âmbito da participação do poder público, destaca-se em 2014 a participação de representantes dos municípios de Olivença e Santana do Ipanema. Já em 2015, também se ampliou a presença do poder público, sobressaíram-se a presença de representantes dos municípios de Santana do Ipanema, de Carneiros e de Senador Rui Palmeira. Os municípios de Ouro Branco e Dois Riachos não apresentam representatividade nas atas analisadas. Porém, faz-se necessário mencionar que, em algumas listas havia assinaturas sem nome de município e/ou associações/entidades representadas, isto dificultou a precisão dos dados referentes à participação no Colegiado.

\section{PROINF: o chamariz para os/as agricultores/as familiares nas plenárias do CODETER?}

Nas plenárias do CODETER, entre os anos de 2014 e 2016, as principais pautas foram, a saber: Declaração de Aptidão (DAP) ao Programa Nacional de Fortalecimento da Agricultura Familiar (PRONAF); Plano Safra; Microcrédito; Assistência Técnica (ATER); Luz para Todos; Programa de Apoio à Formação Superior em Licenciatura em Educação do Campo (PROCAMPO); Programa Nacional de Acesso ao Ensino Técnico e Emprego (PRONATEC); o Programa de Aquisição de Alimentos (PAA); Programa Nacional de Alimentação Escolar (PNAE) e PROINF. 
Observou-se maior participação dos atores sociais nas plenárias do Colegiado que tratavam das chamadas para o PROINF. Segundo a representação da Assessoria Técnica do Território do Médio Sertão, há um esvaziamento da sociedade civil nas plenárias quando se compara com os anos anteriores a 2014. No entanto, evidenciou-se a significativa presença dos atores sociais nos dias em que a pauta das reuniões estava relacionada às chamadas do PROINF ou as discussões tinham ligação direta com as propostas dos projetos de Infraestrutura e Serviços.

Em 2014, houve um incremento na participação do Colegiado, principalmente, em virtude da presença do NEDET/UFS. O referido Núcleo Técnico foi essencial para modificar os rumos da gestão territorial. A atuação da Universidade no Território trouxe densidade técnico-científica e administrativa à Gestão e certamente, representou mais confiança aos atores sociais na consolidação das propostas do PROINF.

De acordo com as atas e as listas de frequência, produzidas pela representação da Assessoria Técnica, no ano de 2015, fica nítida uma maior participação da gestão territorial quando o assunto envolvia as questões dos projetos de Infraestrutura e Serviços. Os meses de Janeiro e Julho apresentaram maior presença do poder público, técnico e da sociedade civil. Em contrapartida, o menor número de participantes foi no mês de outubro em que a pauta discussão foi sobre gestão.

Das políticas enfatizadas nas pautas das reuniões, as propostas sobre os PROINFs ganharam maior destaque durante os três anos. Os PROINFs colocados em questão na plenária foram os dos anos de 2006, 2013 e 2014. Em relação ao PROINF 2006, abordou-se nas plenárias a paralisação da obra do abatedouro frigorífico. Sobre os demais anos, discutiuse sobre os problemas do uso do caminhão e a possível devolução ao Consórcio para o Desenvolvimento da Região do Ipanema (CONDRI). Ademais, apresentaram-se as dificuldades e as limitações referentes ao uso dos tratores e dos caminhões por todos que fazem parte do Território. As discussões são referentes às dificuldades na manutenção das máquinas e da logística para o deslocamento desses equipamentos para os demais municípios. Conforme as atas do Colegiado, esses são alguns dos obstáculos ainda não superados de maneira consistente entre os interessados. Mencionou-se também que, os tratores continuam na sede do proponente, Prefeitura de Santana do Ipanema, aguardando a solicitação através dos planos de trabalho para serem liberados para atender aos/as demais agricultores/as familiares. 
A participação e a frequência nas reuniões dependem da direção dada às propostas. Observa-se que ao colocar em pauta os PROINFs na cadeia produtiva da ovinocaprinocultura, os representantes dos municípios com os maiores rebanhos compareciam. Assim, predominavam a participação dos atores sociais de Maravilha, Santana do Ipanema, Senador Rui Palmeira e São José da Tapera. Nesse contexto, os conflitos entre os/as agricultores/as familiares fazem-se evidente, pois as propostas aprovadas indicam a melhoria de uns e a invisibilidade de outros do Território. As deliberações para as ações do PROINF nem sempre estão em consonância com a coletividade do Território, pois "muitas vezes é orientada por apenas um pequeno grupo dentro do território, que, amparado pelo discurso da coletividade, decide por ações setoriais e pouco abrangentes e sem articulação entre os sistemas produtivos dos espaços rurais dos territórios" (SOUZA, S., 2015, p. 67).

A ideia de desenvolvimento territorial rural e a possibilidade de novas oportunidades técnicas, como o PROINF, são compreendidas pelo/a agricultor/a familiar como o novo que chega para mudar o espaço e minimizar os problemas de produção enfrentados nos períodos de seca. Os/as agricultores/as familiares com a produção escassa e a pecuária deficiente tendem apoiar suas expectativas em projetos do PROINF e dele busca extrair a potencialidade e possibilidade de contribuição para a as atividades desempenhadas pela agricultura familiar sertaneja. As ações de Infraestrutura e Serviços mostram-se como uma possibilidade de mudança territorial. Nesse contexto, para aqueles que vivem sem condições, a força de atração se materializa na oportunidade, talvez a única, de melhorar a produção.

Possivelmente, o PROINF é a chave de atração do Colegiado, no entanto, como força que atrai também pode apresentar força inversa. As propostas de Infraestrutura e Serviços inevitavelmente são relevantes para os/as agricultores/as familiares, pois se considera a necessidade de aproximar-se das condições de oportunidades de acesso a novas técnicas e de atuação mais realista nas atividades agropecuárias. Porém, propostas sem ação compromete a formação de uma gestão territorial coerente direcionada aos principais interessados, os/as agricultores/as familiares.

Faz-se imprescindível mencionar que nas reuniões destaca-se insistentemente a importância da participação dos representantes das entidades civis e a regularidade da frequência nas plenárias do Colegiado. Ressalta-se ainda, que a prioridade das ações seja para os mais assíduos nas reuniões. Desse modo, questiona-se: como atuam os/as agricultores/as familiares nas plenárias do CODETER? 


\section{O cenário territorial do Colegiado: a atuação dos/as agricultores/as familiares}

Nos primeiros dias de contato com os atores sociais, buscou-se analisar mais de perto a participação e o comportamento deles à luz do processo de tensão e das relações de poder firmadas nos espaços de atuação. Observou-se durante os trabalhos de campo, entre os anos de 2016 e 2017, a organização territorial dos atores sociais na arena de discussões com o objetivo de entender a atuação dos/as agricultores/as familiares no Colegiado de Desenvolvimento Territorial. As reuniões aconteciam mensalmente no auditório da Prefeitura Municipal de Santana do Ipanema, em linhas gerais, às quintas-feiras, com início às 9 horas e término às 12 horas. A Assessoria Territorial tinha como responsabilidade informar aos atores sociais do Colegiado, o dia, o horário, o local, e reservar o espaço onde seriam realizadas as plenárias ou reuniões do Núcleo Diretivo.

O auditório da Prefeitura de Santana do Ipanema, onde se realizavam as plenárias, apresenta estrutura circular parecida com a configuração de um anfiteatro. As cores alaranjadas das cadeiras amenizavam o tom de seriedade do ambiente. A plenária começava com uma breve apresentação dos atores sociais que estavam presentes. Solicitavam-se o nome e a representação social. Como pauta, predominavam os apontes sobre os principais impasses e os aspectos situacionais dos PROINFs. A discussão era voltada, regularmente, as chamadas dos PROINFs, assim como, os PROINFs paralisados e os que ainda não haviam iniciados, ou seja, os que apresentam problemas de conclusão. Outro ponto de pauta bastante discutido era sobre a construção do Plano Nacional de Desenvolvimento Territorial Rural Sustentável Solidário (PNDRSS).

$\mathrm{Na}$ maior parte das reuniões que se acompanhou nem um terço das poltronas eram ocupadas. Os espaços sempre muito vazios despertavam a insatisfação e descrédito dos representantes da sociedade civil, principalmente dos/as agricultores/as familiares. Os representantes da sociedade civil quase sempre sentavam atrás, na maioria das vezes, nas duas últimas fileiras de cadeiras do auditório. Quando estas cadeiras já haviam sido ocupadas, surgia certa resistência em se aproximar das primeiras fileiras. Vestiam-se simples, natural do/a agricultor/a familiar, sem muita sofisticação. Os olhares confusos, preocupados e receosos eram nítidos. Embora fossem apenas olhares, eles diziam muito.

No decorrer das discussões notava-se pelas expressões faciais de alguns/as agricultores/as familiares certa insatisfação, que variavam conforme a pauta. Na maioria das vezes, estas insatisfações eram expostas entre si, em tom de voz baixa, quase sussurros. $\mathrm{O}$ 
Entrevistado III ao refletir sobre a importância do Colegiado como instância de discussão menciona: "é importante para nós conhecer as coisas né. Conhecer as propostas que tá ẩ" (Entrevistado III, 2017, [sic]). Mas, contraditoriamente, ao perguntar se ele conhecia o PTDRS do Território, a resposta foi: "não!" Embora esse mesmo entrevistado estivesse participando da construção do novo PTDRS, denominado Plano Territorial de Desenvolvimento Rural Sustentável e Solidário (PNDRSS). O jogo de interesses torna secundária a ideia macro da política em questão. Cada município, cada agricultor/a familiar, enfim, cada representação, tem interesses. Há um evidente descompasso na relação entre o coletivo enquanto Território do Médio Sertão e o coletivo das representações. Assim, discrição e cansaço desenham o território dos agricultores e agricultoras familiares concentrados nas últimas fileiras do auditório. É válido mencionar que a maior parte dos integrantes das reuniões era mulheres.

Respirações mais fortes ou sussurros eram ouvidos todas as vezes que o assunto era a situação do abatedouro frigorífico e dos tratores. As principais dúvidas eram direcionadas ao Secretário de Agricultura e outros representantes do município de Santana do Ipanema, que se sentavam nas poltronas localizadas no meio do auditório. As indagações enfatizadas pelo agricultor/a familiar pautavam-se sempre nas seguintes interrogações: "Cadê os tratores?"; "Ninguém recebeu nada ainda, como fazer?"; "Os tratores só ficarão aqui em Santana?"; "E o abatedouro, já não se fala mais? Como vamos resolver?".

A cada incerteza enfatizada, os representantes do poder público tentavam esclarecer as dúvidas dos vistos como "corajosos" por indagarem sobre a problemática. As respostas orientavam-se nas seguintes proposições: 1. Falta de logística para levar os tratores. 2. Precisa ter habilidade para trabalhar com as máquinas. Ficar muito tempo parado vai precisar de revisão. 3. Sobre o abatedouro, estamos aguardando. 4. Deve haver articulação do Colegiado para definir e cuidar dos impasses que envolvem a política. 5. É necessário adiantar os projetos, planos de trabalho, porque existem os problemas de gestão que são provisórios, como a prefeitura, Estado e no âmbito federal. Estas questões eram sempre destacadas pelos atores institucionais públicos. As perguntas de insatisfação misturavam-se com a morosidade dos discursos de outras políticas públicas vivenciadas pelos/as agricultores/as familiares. Assim, de um lado, tentava-se esclarecer o motivo da paralisação e o não funcionamento dos projetos adquiridos. De outro, para aqueles que conseguiam se expressar, predominava a solicitação e agilidade no planejamento final dos projetos em debate. 
Um ou dois agricultores/as questionavam e manifestavam suas insatisfações com a Prefeitura de Santana do Ipanema como proponente dos dois PROINFs que mais se destacavam nos debates. Há em relevo um evidente conflito territorial pela hipótese levantada pelos/as agricultores/as familiares de que Santana do Ipanema ficaria com os tratores para a prefeitura e esqueceria os outros municípios.

Neste contexto, é válido mencionar que, de modo geral, as intervenções citadas pelos atores da sociedade civil eram determinadas de acordo as referências que tinham de outros Territórios da Cidadania. Mas se por um lado, tinham-se conflitos territoriais evidentes, por outro lado, o funcionamento da gestão e o atraso ou ausência da apresentação do plano de trabalho pelos/as agricultores/as familiares também foram constantemente mencionados. O plano de trabalho era solicitado pelo Secretário de Agricultura do Município de Santana do Ipanema para disponibilizar os tratores aos grupos sociais definidos pelos representantes da sociedade civil, ou seja, os que estavam representados no Colegiado. Ao ser questionado sobre o plano de trabalho o Entrevistado III diz: "não, isso a gente não fez ainda, mas vou fazer para ver se a gente recebe né!" (Entrevistado III, 2017, [sic]). A entrevistada IV, com dúvidas sobre como seria o plano de trabalho, não soube responder se a Associação que representa entregou ou não o referido plano.

Os arranjos políticos-institucionais para a gestão do Território dependem do poder do conhecimento e da articulação política. Mas nem sempre os/as agricultores/as familiares estão preparados para esse "jogo de poder", um dos elementos desse despreparo certamente é o alto índice de analfabetismo na faixa etária com mais de 25 anos como constatado no último censo do IBGE.

\section{CONSIDERAÇÕES FINAIS}

A estratégia territorial dos Territórios da Cidadania denota uma narrativa coletiva no processo de integração das políticas públicas para a agricultura familiar. No entanto, percebese uma aglutinação individualista quando são materializadas as propostas do PROINF. Na perspectiva da gestão territorial, notam-se interesses de um determinado público que participa do Colegiado. O espaço de discussão torna-se arena de poder na tomada de decisões. O interesse de determinado grupo é evidenciado, o que possivelmente tende a excluir os grupos ou associações não participantes. Os sujeitos (in)visíveis ficam fora das pautas da gestão das 
políticas de desenvolvimento. A proposta de coletividade é sucumbida por um processo mais perverso e desagregador, pois os interesses são diversos e as intencionalidades também.

Assim, os conflitos surgem destes interesses que nem sempre correspondem ao grupo, mas que são forçados a decidir sobre o uso da técnica disponibilizada. $\mathrm{O}$ uso dos tratores é um exemplo materializado no Médio Sertão Alagoano, pois a demanda para o uso da máquina depende da logística de transporte, do custo do combustível, manutenção e disponibilidade do tratorista. As condições de uso provocam desistência e discussões sobre o destino dos tratores. Nessa perspectiva, tem-se o objeto geográfico separado da ação social.

Os projetos do PROINF se destacam como força para atrair o/a agricultor/a familiar. A insustentabilidade no Território segue um movimento de ação, uma vez que atrai para afastar. Nesta contradição, o/a agricultor/a familiar torna-se refém dos projetos num processo de (des)construção da política. A promessa efetivada está à mercê da eficácia. A proposta de fortalecimento da agricultura familiar fica comprometida e a autonomia produtiva reduz-se à dependência.

\section{REFERÊNCIAS}

BRASIL, Ministério do Desenvolvimento Agrário. Secretaria de Desenvolvimento Territorial. Marco referencial para apoio ao desenvolvimento de territórios rurais. Série documentos institucionais 02-2005. Brasília: SDT, 2005.

CANÇADO, A. C; TAVARES, B.; DALLABRIDA, V. R. Gestão Social e Governança Territorial: Interseções e especificidades teórico-práticas. Revista Brasileira de Gestão e Desenvolvimento Regional, Taubaté, SP, v. 9, n. 3, p. 313-353, set-dez., 2013.

CARVALHO, C. P. de. Análise da reestruturação produtiva da agroindústria sucroalcooleira alagoana. 3. ed. Maceió: EDUFAL, 2009.

CARVALHO, C. P. de. Economia popular: Uma via de modernização para Alagoas. 3. ed. Maceió: EDUFAL, 2008.

DELGADO, N. G.; GRISA, C. Políticas de desenvolvimento territorial e pobreza rural no Brasil: Análise das institucionalidades e da governança. Estudos Sociedade e Agricultura, Rio de Janeiro, v. 22, n. 1, p. 132-163, 2014.

DINIZ, E. Governabilidade, governance e reforma do Estado: considerações sobre o novo paradigma. Revista do Serviço Público, v. 120, n. 2, mai-ago, 1996.

IBGE. Instituto Brasileiro de Geografia e Estatística. Censo Demográfico - Alagoas, 2010.

PTDRS. PLANO DE DESENVOLVIMENTO RURAL SUSTENTÁVEL. Ministério do Desenvolvimento Agrário. Secretaria de Desenvolvimento Territorial. Plano Território de Desenvolvimento Rural Sustentável do Médio Sertão Alagoano. Brasília: SDT, 2010. 
RAFFESTIN, C. Por uma Geografia do Poder. São Paulo: Ática, 1993.

RODRIGUES. S. A. S.; NASCIMENTO, P. O. do.; SILVA, A. L. da. Desenvolvimento e políticas públicas: Análise da execução do PROINF 2005-2014 no Território do Médio Sertão de Alagoas. XXIII Encontro Nacional de Geografia Agrária (ENGA), São Cristóvão, UFS, 2016.

SANTOS, L. M. R. dos; OLIVEIRA, E. R. S. dos S.; COSTA, J. E. da. Execução do PROINF nos Territórios da Cidadania do Agreste e do Litoral Norte do estado de Alagoas:

Contradições e similaridades. XXIII Encontro Nacional de Geografia Agrária (ENGA), São Cristóvão, UFS, 2016.

SANTOS, M. A urbanização brasileira. 5. ed. São Paulo: Editora da Universidade de São Paulo, 2013.

SANTOS, M. A natureza do espaço: técnica, e tempo, razão e emoção. 4. ed. São Paulo: Editora da Universidade de São Paulo, 2012.

SAQUET, M. A. Abordagens e concepções de território. 2. ed. São Paulo: Expressão Popular, 2010.

SILVA, J. A. da. PROINF no Território da Cidadania do Médio Sertão de Alagoas: um caminho para o desenvolvimento territorial rural? Dissertação (Mestrado em Geografia) Universidade Federal de Sergipe, São Cristóvão, SE, 2018.

SOUZA, M. L. de. Os conceitos fundamentais da pesquisa sócio-espacial. 2. ed. Rio de Janeiro: Bertrand Brasil, 2015.

SOUZA, S. P. de. Políticas públicas e desenvolvimento territorial: o Programa Territórios da Cidadania no estado de São Paulo. Tese de doutorado. Presidente Prudente: UNESP, 2015.

Recebido em Março de 2020

Aceito em Maio de 2020

Publicado em Julho de 2020 